\title{
Local Candidate Effects in Canadian Elections
}

\author{
Benjamin Allen Stevens, University of Toronto \\ Md Mujahedul Islam, University of Toronto \\ Roosmarijn de Geus, University of Toronto \\ Jonah Goldberg, University of Toronto \\ John McAndrews, University of Toronto \\ Alex Mierke-Zatwarnicki, Harvard University \\ Peter John Loewen, University of Toronto \\ Daniel Rubenson, Ryerson University
}

\begin{abstract}
What impact do local candidates have on elections in single member district plurality electoral systems? We provide new evidence using data from a large election study carried out during the 2015 Canadian federal election. We improve on the measurement of local candidate effects by asking over 20,000 survey respondents to rate the candidates in their constituency directly. We present three estimates. We find that when all voters are considered together, local candidate evaluations are decisive for approximately 4 per cent of voters. Second, these evaluations are decisive for the outcome of 10 per cent of constituency contests. Third, when models are estimated for each constituency, we find significant candidate evaluation effects in 14 per cent of constituencies.
\end{abstract}

\section{Acknowledgements:}

This research was made possible by an SSHRC Insight Grant for the Local Parliament Project. The authors thank Maxime Héroux-Legault for research assistance and Eve Bourgeois for translation services.

The first six authors are listed in alphabetical order. Loewen and Rubenson are the principal investigators of the Local Parliament Project.

Benjamin Allen Stevens, School of Public Policy and Governance, University of Toronto, Canadiana Building, 14 Queen's Park Crescent West, Toronto ON Canada, M5S3K9, email: b.allenstevens@utoronto.ca - Research Associate.

Md Mujahedul Islam, Department of Political Science, University of Toronto, Sidney Smith Hall, 100 St. George Street, Toronto ON Canada, M5S 3G3, email: mujahed.islam@mail.utoronto.ca - PhD student. 
Roosmarijn de Geus, Department of Political Science, University of Toronto, Sidney Smith Hall, 100 St. George Street, Toronto ON Canada, M5S 3G3, email: roosmarijn.degeus@utoronto.ca - Postdoctoral Fellow.

Jonah Goldberg, Department of Political Science, University of Toronto, Sidney Smith Hall, 100 St. George Street, Toronto ON Canada, M5S 3G3, email: jonah.goldberg@utoronto.ca - PhD student.

John McAndrews, Department of Political Science, University of Toronto, Sidney Smith Hall, 100 St. George Street, Toronto ON Canada, M5S 3G3, email: john.mcandrews@utoronto.ca - SSHRC Postdoctoral Fellow.

Alex-Mierke-Zatwarnicki, Department of Government, Harvard University, 1737 Cambridge Street, Cambridge, MA 02138 US, email: amierkezatwarnicki@g.harvard.edu - PhD student.

Peter John Loewen, Department of Political Science, University of Toronto, Sidney Smith Hall, 100 St. George Street, Toronto ON Canada, M5S 3G3, email: peter.loewen@utoronto.ca - Director of the School of Public Policy and Governance / Professor, Department of Political Science.

Daniel Rubenson, Department of Politics and Public Administration, Ryerson University, Jorgensen Hall 279, 350 Victoria Street, Toronto ON Canada, M5B 2K3, email: rubenson@ryerson.ca - Associate Professor. 
In Canada, as in many Anglo-American democracies, election campaigns occur at once at the national and local level. Media attention is typically focused on national campaigns (Mendelsohn, 1993; Trimble and Sampert, 2004), which have become increasingly leader-driven. Nonetheless, candidates running in single member plurality districts operate locally run campaigns with at least some autonomy (Carty, 2002; Carty and Young, 2012; Coletto et al., 2011; for an American example, see Enos and Hersh, 2015) and are, at least to some degree, elected to represent local interests in the House of Commons. This raises an important empirical question: To what degree do local candidates matter in Canadian federal elections? ${ }^{1}$ Existing literature provides contradictory results on the effects of local candidates. At least some of this is likely attributable to a lack of detailed data on voters' actual views of local candidates (Simpson, 2002; Blais et al., 2003; Roy and Alcantara, 2015; Blais and Daoust, 2017).

This paper builds on previous work in two important ways. First, we employ novel data from the 2015 Canadian federal election (Loewen and Rubenson 2018). ${ }^{2}$ Our data consists of a much larger sample of respondents than typical election studies. It also contains a direct measure of voters' evaluations of local candidates. These two factors allow for better-powered analysis. Second, we present three estimates of local candidate effects, rather than a single estimate. In the first approach, we estimate the share of voters for whom a local candidate rating was decisive. In the second approach, we estimate the number of ridings in which candidate effects appeared decisive and caused a seat to change hands. In the third approach, we estimate riding-level variation in local candidate effects, demonstrating that local candidates in fact have large effects on the vote, but in a small number of constituencies. As the existing literature mostly uses the first approach, we introduce two additional estimates of local candidate effects. We show that the importance of local candidates (or: "the local candidate effect") can be measured in different ways, both at the 
level of individual vote choice, as well as at riding-level election outcomes. All three estimates return broadly similar results, strengthening our conclusion as to the positive but limited effect of local candidates.

We conclude the following. Evaluations of local candidates are decisive for approximately 4 per cent of voters (3.7\% outside Quebec and 6.1\% inside Quebec). Evaluations of local candidates prove decisive for the outcome of approximately 10.4 per cent of constituency contests $(9.3 \%$ outside Quebec and 14.1\% inside Quebec). When considered on a riding-by-riding basis, there is an impressive range in the size of local candidate effects, but they only appear statistically significant in a minority of constituencies (In 122 out of 325 constituencies, at least one candidate from the three major parties had a significant effect on vote choice). ${ }^{3}$ Taken together, these results largely confirm previous work on the important but limited effect of local candidates.

Our paper proceeds as follows. We first review the existing literature on local candidate effects and situate our paper within this line of research. We next describe our data and estimation strategies. We then present our results and conclude.

\section{Local Candidate Effects in Canadian Elections}

Political parties have adjusted to Canada's geographically diverse electoral landscape by decentralizing their campaigns, providing a substantial degree of autonomy to local candidates, and allowing local candidates to adapt their strategies and tactics to local contexts (Carty, 2002; Carty and Young, 2012; Coletto et al., 2011; Loewen et al., 2015). Furthermore, the vast majority 
of official party candidates are chosen by local party members, increasing the link between local candidates and their constituents. Within such a decentralized context, it might thus be expected that local candidates and their campaigns exert an important influence on electoral outcomes in Canada. Various scholars have sought to determine the size of this local candidate effect, but results have been mixed. Clarke et al. (1979) and Irvine (1982), for example, concluded that local candidate effects in Canadian elections were minimal. Other research, however, has found positive evidence of candidate effects. Cunningham (1971) argues for instance that 10 per cent of voters in the 1968 federal election cast their votes based on their personal affinity for local candidates. Blais et al. (2003) find that 44 per cent of Canadian voters expressed a distinct preference for local candidates in the 2000 elections. The authors estimate that the quality of local candidates was the decisive factor for 5 per cent of all voters on election day. More recently, Roy and Alcantara (2015) present experimental results showing that strong local candidates can yield a 10 percentage point bounce in local races. In looking at the 2015 federal election, Blais and Daoust (2017) study candidate effects across British Columbia, Ontario, and Quebec, and find that 48 per cent of voters in those provinces expressed a preference for a particular candidate. Of those voters, 9 per cent held incongruent preferences, such that their preferred party and candidate did not align. Approximately 40 per cent of those voters voted for the candidate over the party, suggesting that, for a small group of voters, candidates were more important than parties or national leaders. ${ }^{4}$

In addition to establishing that local candidates exert an effect on election outcomes, researchers have also sought to determine what qualities of local candidates are most likely to increase their share of the vote. In other words, what makes for a "strong" local candidate? In the Canadian context, Roy and Alcantara (2015) find that voters are more likely to support so-called "strong" 
local candidates after learning more about their personal backgrounds, while Krashinsky and Milne $(1983,1985,1986)$ have shown that incumbent members of Parliament tend to receive a five percentage point boost on election day. In research that extends beyond the Canadian context, three additional performance-boosting candidate characteristics have been identified: political experience (Krebs, 2001; Marsh, 1987; Shugart et al., 2005; Tavits, 2010), the candidate's residential proximity to the constituency (Arzheimer and Evans, 2012, 2014; Evans et al., 2017), and personal qualities, such as occupation or appearance (Ahler et al., 2015; Campbell and Cowley, 2013; Keeter, 1987; Schoen and Schumann, 2007).

Apart from candidate characteristics, the importance of a strong local campaign has also been emphasized, especially in the US context (Clarke et al., 2004; Eldersveld, 1964; Huckfeldt and Sprague, 1995; Wielhouwer and Lockerbie, 1994). Fundraising, volunteer recruitment, and spending levels are key determinants of local candidate success (Heintzman, 1991; Johnston, 1987; Johnston et al., 1989; Johnston et al., 2011; Pattie et al., 1995). Local volunteer recruitment enhances candidates' vote shares: local canvassing, door knocking, and flyer distribution are critical in both vote choice (Eagles, 1993; Barton et al., 2014; Denver et al., 2004; Dewan et al., 2014; Marsh, 2004; Pattie and Johnston, 2003; Whiteley and Seyd, 2003) and turnout (Gerber and Green, 2000; Karp and Banducci, 2007; Karp et al., 2008). Although evidence therefore exists to suggest that local candidates matter in shaping Canadian electoral outcomes, most studies find modest effectsranging between five and ten percentage points - across various measures.

In this paper we explore the effect of local candidates on the 2015 federal election and thus provide an up to date analysis of local candidate effects in Canadian elections. The 2015 election is a particularly interesting case study, as the nature of political campaigns has changed 
significantly over the last few decades. Contemporary election campaigns are characterized by high levels of media attention, with a particular focus on television and modern forms of social media. High levels of media attention have encouraged a greater focus on national party leaders. For example, Mendelsohn (1996) and Gidengil et al. (2002) report evidence that individuals more exposed to media coverage of the election put greater emphasis on leaders. Ohr (2011) argues that changing patterns in political communication have resulted in leaders mattering more for vote choice not only in leader-centric systems such as the United States, but also in parliamentary systems. Leaders may have been especially focal in the 2015 Canadian federal election. Both the Liberals and New Democrats had rookie leaders - Justin Trudeau and Thomas Mulcair-and many saw the election as a referendum on the leadership of Stephen Harper. The increased levels of attention to national party leaders may suggest that local candidate effects might be expected to be much smaller in 2015 compared to past Canadian elections (Blais et al., 2003; Roy and Alcantara, 2015). On the other hand, the 2015 election resulted in a change in government and saw an especially large number of new MPs elected to office. The large turnover of individual MPs may suggest that the quality and appeal of local candidates were important to individuallevel vote choice and to which candidates were elected.

\section{Data}

In order to estimate the effect of local candidates in the 2015 Canadian election, we rely on a novel dataset, the Local Parliament Project. The Local Parliament Project, fielded over the course of the 2015 federal election, is the largest ever election survey of Canadians. The study was conducted online with an average of 622 respondents per day. Respondents were provided by a large online sampling firm (full details are available Appendix B). The sample was designed to be nationally representative over a three-day window. Among other things, respondents were asked about 
their vote choice, likelihood of going to the polls, past turnout and votes, their partisan identification, their positions on more than thirty major issues, and their expectations of the likely victor in their riding and at the national level.

The total effective size of the Local Parliament Project survey is substantial: 20,115 respondents with an indicated vote choice, with a riding-level average of $56.1(\mathrm{sd}=22.3) .{ }^{5}$ This allows us to not only estimate the effect of local candidates at the aggregate level, but also to estimate the constituency-level consequences of these candidate effects. What is more, previous studies on local candidate effects rely on survey questions such as: "Is there a local candidate that you particularly like in your riding?" (Blais et al., 2003; Blais and Daoust, 2017). This limits analysis of effects to a single candidate, and perhaps only to candidates who are liked much more, rather than only marginally more, than others. In contrast, the Local Parliament Project survey asked respondents how they feel about each of the major party candidates in their riding. Respondents were asked to rate candidates from all parties (Conservatives, Liberals, Greens, New Democrats and, in Quebec, the Bloc Québécois) on a scale from zero to 100. The names of the local candidates in the respondent's riding were used in the question. In addition, for a randomly selected share of respondents $(\sim 50 \%)$, the study included the candidate's party in addition to the candidate's name. By using candidates' names, we obtain a more accurate measure of respondents' attitudes toward their local candidates. Whereas Blais et al. (2003) find that 44 per cent of voters indicate that there is one local candidate they particularly preferred, we find substantially more variation in preferences for local candidates. Following Tables A1 and A2 in Appendix A, we find that at least three quarters of respondents are able or willing to provide evaluations of at least one candidate. While not all respondents hold strong preferences, the vast majority can express some 
differences in their evaluations across candidates. Moreover, the modal respondent in both Quebec and the rest of Canada provides evaluations of all candidates presented to them. ${ }^{6}$

\section{Estimation strategy}

Our work has three major empirical objectives. First, we want to determine the extent to which local candidates had an impact on the 2015 election at the individual level (following Blais et al., 2003). Second, we extend this to the constituency level. Third, we seek to ascertain the variation in individual-level local candidate effects across constituencies. Although the existing literature focuses mostly on objective one, we argue that the "local candidate effect" can be conceptualized in more ways than one. Local candidate evaluations may matter for individuals as part of their vote decision (estimate one), but local candidates may also matter in the sense that they can prove decisive in causing a seat to change hands (estimate two). Finally, we estimate the number of ridings in which local candidates exerted a statistically significant effect in models estimated within each constituency (estimate three). We thus provide three different estimates of the local candidate effect, which, as we shall show, all support the same conclusion.

Our approach to answering the first question follows closely from Blais et al. (2003). We first estimate a multinomial logit model in which the dependent variable is vote choice for one of the five major parties. Our key variables are feeling thermometer evaluations of the local candidates, ranging from $0-100$, which is recoded to range between -1 and +1 with a neutral mid-point of zero. We add as controls leadership ratings and party identification, as well as incumbency status of the candidates and policy preferences on taxation, social policy, and foreign affairs. We likewise control for respondents' age, income, and gender. A full description of every variable is available in Appendix B.7 Finally, to capture regional variation in the baseline of support for each 
party, we add in fixed effects for provinces. While such models are not parsimonious (Achen, 2002), they do allow us to plausibly demonstrate that the net effects of candidate ratings are not merely a stand in for other variables. ${ }^{8}$ Our models correctly classify the votes of 86.7 per cent of our respondents outside of Quebec and 84.0 per cent of respondents in Quebec, for an average correct classification of 85.9 per cent. ${ }^{9}$

After this model is estimated, we first post-estimate predicted likelihoods of voting for each party with all variables at their observed levels. We classify an individual as voting for the party with the highest predicted likelihood. We then set the observed value of candidate ratings to zero (the midpoint of the scale) and generate new estimates of the predicted likelihoods of voting for each party. Individuals are again classified as voting for the party with the highest predicted likelihood. After assigning this counterfactual vote, we compare the predicted vote under the two scenarios. The share of voters whose predicted vote changes is equivalent to an estimate of the share of voters for whom the local candidates were decisive. This follows the essential logic of Blais et al. (2003).

We provide an extension on this method. The size of our dataset affords us an average of 56.1 effective respondents per constituency. ${ }^{10}$ Accordingly, we go a step further by aggregating the predicted votes for each party within each riding. By identifying the party with the most predicted votes in a constituency, we can also identify a predicted winner in each constituency. If we compare our predicted winners using this method to the reported vote choice of survey respondents, we find that we accurately predict 86.3 per cent of ridings. Following this, we once again zero out the local candidate effects and generate new predictions for votes, which are then aggregated up into new riding-level predictions. Identifying the raw number of predicted seats 
that would change hands in the absence of candidate effects gives us another estimate of the importance of local candidates.

Our approach to answering the final question - to what extent does the size of candidate effects vary across constituencies - is as follows. First, we re-estimate our vote choice model separately in every riding for each of the three major parties, which generates 975 estimates. For computational ease and efficiency, these are estimated as linear probability models. Each model includes all of the control variables presented in Table 1 . We then characterize the range of local candidate effects, primarily by examining the distributions of both effect sizes and statistical significance across ridings for the candidate rating associated with the dependent variable (for example, the effect of the Conservative candidate rating for the Conservative candidate). Taken together, these results allow us to examine how much local candidate effects vary and how often they matter statistically across constituencies.

\section{Results}

Our results begin in Table 1, which presents estimates of a multinomial logistic regression of vote choice for the four major parties outside of Quebec. The incumbent Conservative party is the reference group. We find that evaluations of the three main party leaders-Harper, Trudeau and Mulcair-exerted a significant effect on vote choice, in the expected direction. Likewise, partisan identification exerts a significant effect on vote choice. Interestingly, we only find minimal effects of issue positions. Only views on international security (a scale including views on terrorism and military spending) seems to have been important to voters in deciding which party to vote for. We find incumbency effects for the NDP and the Green party, but not for the Conservative or Liberal parties. None of our provincial fixed effects are significant. The same is largely true for 
the model in Quebec (Table 2), although here positions on taxes also mattered to vote choice and incumbency status has no effect. Also, as expected, evaluations of Bloc Québécois leader Gilles Duceppe positively affected vote choice for the BQ in Quebec.

Inspection of the four candidate assessments across three vote choice comparisons suggests that they significantly affect vote choice in seven of twelve cases. The five non-significant cases are either the effect of Green candidate assessments (in two of three comparisons), the effect of other candidate assessments on the likelihood of voting for the Green candidate, or in one case the effect of NDP candidate evaluations on Liberal versus Conservative vote choice. Results are less consistent in the Quebec case, as presented in Table 2. In that instance, our five candidate ratings across four pairwise comparisons generates twenty coefficients. We find significant candidate results in seven of twenty cases. As others have observed (for example, Blais et al., 2003, 662), local factors perhaps matter less in Quebec.

\section{[Table 1 and Table 2 about here]}

Moving beyond a visual inspection of our models, our first formal test is to consider how many individuals would hold a different counterfactual vote if the effect of local candidates was set to zero. According to the models presented in Tables 1 and 2, the percentage of individuals whose vote would differ in the absence of local candidate effects is 3.7 per cent in Canada outside of Quebec and 6.1 per cent in Quebec. We note that these results are largely consistent under various specifications of our key variables (see Tables A5 and A6 in Appendix A) and under different sample restrictions (see Tables A7 through A12 in Appendix A) . Results are also robust to the inclusion of data on campaign spending by local candidates (Tables A15 and A16 in Appendix 
A). These results are largely in line with Blais et al. (2003). After performing a similar analysis, Blais et al. (2003) find that the local candidate was a decisive factor for 5 per cent of voters.

Our second estimation occurs at the level of constituencies. We observe the distribution of predicted votes from the models discussed above and identify a winning candidate in each constituency. We then observe the distribution of votes within constituencies once local candidate effects are set to zero and identify a winning candidate in each constituency. When we compare these two distributions, we find that 10.4 per cent of constituencies would have elected a different MP in the absence of local candidate effects. ${ }^{11}$ This provides important context to the first estimate presented above, as well as to the estimate of Blais et al. (2003) that local candidates are a decisive factor for approximately 5 per cent of the voters. To establish that evaluations of local candidates matter to 5 per cent of the voters does not inform us as to the importance of local candidates to the actual outcome and seat share of an election. After all, the 4 per cent of voters for whom local candidates are decisive may live in non-competitive seats, or they may be clustered in particular ridings. Our second estimate therefore provides important additional insights and suggests that local candidates were decisive in approximately 10 per cent of ridings.

Finally, we consider the heterogeneity of local candidate effects across constituencies. Figure 1 presents the distribution of candidate effects from linear probability models of vote choice for a particular party. Two effects are of note. First, the average candidate effect hovers near zero, though it is more likely to be positive than negative. Second, there are nevertheless some constituencies that have sizeable effects. For example, when we identify the constituency effects for each party that are in the $80^{\text {th }}$ percentile or higher, we find substantively impressive effects. For the top 20 per cent of Conservative, Liberal, and NDP coefficients, the estimated effect of 
moving from neutrality to the highest candidate rating is a 21,37 , and 43 percentage point increase respectively in the likelihood of voting for the candidate. Since these are linear probability models and our candidate ratings range between -1 and +1 the reverse substantive decline would occur if individuals shift from neutral ratings to the most negative candidate rating. Figure 2 considers the statistical significance of these various effects. For each party, we show the distribution of p-values for the estimated local candidate effect. Almost 10 per cent $(9.8 \%)$ of Conservative candidate ratings exercised a statistically significant effect on the vote. For Liberals, the share is 15.1 per cent. For New Democrats, it is 18.8 per cent. At the constituency level, this means that in 122 out of 325 ridings, at least one candidate from these parties had a significant effect.

\section{[Figure 1 and Figure 2 about here]}

\section{Conclusion}

In this paper, we use a uniquely large dataset to assess the effects of local candidates in a single Canadian parliamentary election. We present three different estimates of the "local candidate effect." Across these three broadly different measures we have found consistent if sometimes modest effects attributable to local candidate evaluations. Local candidates matter decisively in between 5 per cent and 14 per cent of constituencies, whether we are considering their effects on votes, on seats, or on the statistical importance of candidate ratings. Moreover, we have also shown substantial variation in just how much local candidate evaluations matter. Thus, while scholars are right in suggesting that the impact of local candidates can be decisive, this is likely not true in some or even most places. 
When and where, then, do local candidates matter? Greater attention needs to be paid to better understanding the factors that contribute to the efficacy of local candidates. We think there are three promising avenues for this research. First, scholars could better understand how campaigns - especially candidate resources, partisan spending, and volunteer engagementcondition local candidate effects. Second, scholars could search for naturally occurring experiments - for example, variation in exposure to candidates generated by redistricting - to obtain better causal identification of candidate effects. Third, scholars could work to better understand how much variation in candidate effects is conditioned by other factors, such as party issue positions and leader ratings. The objective here is not to consider local candidate effects in isolation, but to better understand how candidate effects vary with other factors, and if the effects of candidate ratings act as a substitute for the effects of issue positions or party leaders. Ultimately, this might offer us a chance to classify different types of constituency races according to the importance of these factors.

Finally, our work raises important normative questions about the role and influence of members of Parliament. If local candidates do not matter much or often - if they are the proverbial nobodies 50 yards from Parliament Hill-what are the implications of this for the quality of local representation and influence in Parliament? While there do exist models that allow for substantial influence in Parliament for MPs absent a strong local power base, it is still important to consider the question of the value of locally-contested elections if the local contestants do not matter all that much or all that often. 


\section{ENDNOTES}

1 To clarify, when we use the term "local candidate", we refer to a candidate who runs at the riding level. This does not necessarily imply that these individuals live in the riding where they run. Previous research in the UK context has shown that geographical distance between voters and candidates matters to vote choice (Arzheimer and Evans, 2012, 2014; Evans et al., 2017) and suggests that candidates who live in the same electoral district as their voters receive an electoral benefit from doing so.

${ }^{2}$ Loewen, Peter and Daniel Rubenson (2018). "Local Parliament Project 2015 Canadian Election Survey." The core version of the data is available on Harvard Dataverse:

https://doi.org/10.7910/DVN/DACHKP

${ }^{3}$ A loss of estimates for constituencies results from two factors. First, we exclude the three territorial constituencies. Second, some constituencies have too few respondents to allow for model estimation. In total, we effectively estimate constituency level models for 325 Conservative candidates, 325 Liberal candidates, and 325 New Democratic candidates.

${ }^{4}$ Arithmetically, this would suggest a total local candidate effect of $0.48 \times .09 \times .40=.02$, or 2 per cent of voters.

5 The total number of respondents to the survey was 37,000, but for the purposes of this analysis respondents who did not report a vote choice were excluded $(N=14,198)$. Also excluded were respondents who finished the survey in less than eight minutes $(\mathrm{N}=256)$, respondents who provided the same answer for all issue positions $(\mathrm{N}=26)$, respondents who completed the survey on election day $(\mathrm{N}=53)$ and respondents who provided a postal code that conflicted with their self-reported province $(\mathrm{N}=2,426)$. More information on the survey can be found in Appendix B.

${ }^{6}$ See Appendix A, Table A4, and Figure A1 for an overview of ratings of incumbents and challengers. As expected, respondents were more likely to rate incumbents than challengers; on average, incumbents were rated somewhat more positively than challengers.

7 We control for incumbency because incumbents likely enjoy a fundraising advantage as well as greater name recognition compared to challenger candidates. As such, controlling for incumbency status allows us to estimate the candidate effects net of these factors.

8 Our model includes a larger schedule of variables than the Blais et al. (2003) model. To demonstrate that our results are not a function of the longer list of variables, we re-estimate using a model that includes only the variables included in Blais et al. The results from this model, noted in Tables A5 and A6 in Appendix A, are not substantively different from those estimated from our larger model.

${ }^{9}$ Note that in line with Blais et al. (2003) we analyze Quebec separately from the rest of Canada. The main reason for this is the difference in party systems between Quebec and the rest of Canada. Although Quebeckers have the opportunity to vote for the Bloc Québécois, voters in the rest of Canada do not; as such, respondents in our survey who lived in Quebec therefore evaluated five candidates whereas respondents who lived in the rest of Canada evaluated only four.

${ }^{10}$ We define the effective sample as the number of respondents who stated a vote intention and have nonmissing values on all modeled variables.

${ }^{11}$ If we restrict our estimation only to ridings that we correctly predict then we find that 8.3 per cent of ridings would change.

\section{References}


Achen, Christopher H. 2002. “Toward a New Political Methodology: Microfoundations and ART." Annual Review of Political Science 5(1): 423-450.

Ahler, Douglas J., Jack Citrin, Michael C. Dougal and Gabriel S. Lenz. 2017. “Face Value? Experimental Evidence that Candidate Appearance Influences Electoral Choice." Political Behavior 39(1): 77-102.

Arzheimer, Kai and Jocelyn Evans. 2012. “Geolocation and voting: Candidate-voter distance effects on party choice in the 2010 UK general election in England." Political Geography 31: 301-310.

Arzheimer, Kai and Jocelyn Evans. 2014. "Candidate geolocation and voter choice in the 2013 English County Council elections." Research and Politics July-September: 1-9.

Barton, Jared, Marco Castillo and Ragan Petrie. 2014. “What Persuades Voters? A Field Experiment on Political Campaigning." The Economic Journal 124(574): F293-F326.

Blais, André, Elisabeth Gidengil, Agnieszka Dobrzynska, Neil Nevitte and Richard Nadeau. 2003. “Does the Local Candidate Matter? Candidate Effects in the Canadian Election of 2000." Canadian Journal of Political Science 36(3): 657-664.

Blais, André and Jean-François Daoust. 2017. “What do voters do when they like a local candidate from another party?" Canadian Journal of Political Science 50(4): 1103-1109.

Campbell, Rosie and Philip Cowley. 2014. “What Voters Want: Reactions to Candidate Characteristics in a Survey Experiment." Political Studies 62(4): 745-765.

Carty, R. Kenneth. 2002. “The Politics of Tecumseh Corners: Canadian Political Parties as Franchise Organizations." Canadian Journal of Political Science 35(4): 723-745.

Carty, R. Kenneth and Lisa Young. 2012. “The Local Underpinnings of Electoral Competition in Canada, 1979-2008." Canadian Political Science Review 6(2-3):227-236.

Clarke, Harold D., David Sanders, Marianne C. Stewart and Paul Whiteley. 2004. Political 
Choice in Britain. Oxford: Oxford University Press.

Clarke, Harold D., Lawrence LeDuc, Jane Jenson and Jon Pammett. 1979. Political Choice in Canada. Toronto: McGraw-Hill Ryerson.

Coletto, David, Harold J. Jansen and Lisa Young. 2011. “Stratarchical Party Organization and Party Finance in Canada." Canadian Journal of Political Science 44(1): 111-136.

Cunningham, Robert. 1971. “The Impact of the Local Candidate in Canadian Federal Elections." Canadian Journal of Political Science 4(2): 287-290.

Denver, David, Gordon Hands and Iain MacAllister. 2004. “The Electoral Impact of Constituency Campaigning in Britain, 1992-2001." Political Studies 52(2): 289-306.

Dewan, Torun, Macartan Humphreys and Daniel Rubenson. 2014. “Elements of Political Persuasion: Content, Contact or Cue." The Economic Journal 124(574): F257-92.

Eagles, Munroe. 1993. “Money and Votes in Canada: Campaign Spending and Parliamentary Election Outcomes, 1984 and 1988." Canadian Public Policy 19(4): 432-449.

Eldersveld, Samuel James. 1964. Political parties: a behavioral analysis. Chicago: Rand McNally.

Enos, Ryan D. and Eitan D. Hersh. 2015. “Party Activists as Campaign Advertisers: The Ground Campaign as a Principal-Agent Problem." American Political Science Review 109(2): 252-278.

Evans, Jocelyn, Kai Arzheimer, Rosie Campbell and Philip Cowley. 2017. “Candidate localness and voter choice in the 2015 general elections in England." Political Geography 59: 61-71.

Gerber, Alan S. and Donald P. Green. 2000. “The Effects of Canvassing, Telephone Calls, and Direct Mail on Voter Turnout: A Field Experiment." American Political Science Review 94(3): 653-663.

Gidengil, Elisabeth, André Blais, Neil Nevitte and Richard Nadeau. 2002. “Priming and 
Campaign Context: Evidence from Recent Canadian Elections," working paper.

Heintzman, D. Keith. 1991. “Electoral competition, campaign expenditure and incumbency advantage." Issues in Party and Election Finance in Canada 5: 97-156.

Huckfeldt, R. Robert and John Sprague. 1995. Citizens, Politics and Social Communication: Information and Influence in an Election Campaign. Cambridge: Cambridge University Press.

Irvine, William P. 1982. "Does the Candidate Make a Difference? The Macro-Politics and MicroPolitics of Getting Elected." Canadian Journal of Political Science 15(4): 755-782.

Johnston, Ronald J., Charles J. Pattie, David Cutts, Edward Fieldhouse and Justin Fisher. 2011. “Local Campaign Spending at the 2010 General Election and Its Impact: Exploring What Wider Regulation has Revealed." The Political Quarterly 82(2): 169-192.

Johnston, Ronald J. 1987. Money and Votes: constituency campaign spending and election results. London: Croom Helm.

Johnston, Ronald J., Charles J. Pattie and L. C. Johnston. 1989. “The impact of constituency spending on the result of the 1987 British general election." Electoral Studies 8(2): 143155.

Karp, Jeffrey A. and Susan A. Banducci. 2007. “Party Mobilization and Political Participation in New and Old Democracies." Party Politics 13(2): 217-234.

Karp, Jeffrey A., Susan A. Banducci and Shaun Bowler. 2008. "Getting Out the Vote: Party Mobilization in a Comparative Perspective." British Journal of Political Science 38(1): 91112.

Keeter, Scott. 1987. “The Illusion of Intimacy: Television and the Role of Candidate Personal Qualities in Voter Choice." Public Opinion Quarterly 51(3): 344-358.

Krashinsky, Michael and William J. Milne. 1983. “Some Evidence on the Effect of Incumbency 
in Ontario Provincial Elections." Canadian Journal of Political Science 16(3): 489-500.

Krashinsky, Michael and William J. Milne. 1985. “Additional Evidence on the Effect of Incumbency in Canadian Elections." Canadian Journal of Political Science 18(1): 155-165.

Krashinsky, Michael and William J. Milne. 1986. “The Effect of Incumbency in the 1984 Federal and 1985 Ontario Elections." Canadian Journal of Political Science 19(2): 337-343.

Krebs, Timothy B. 2001. "Political Experience and Fundraising in City Council Elections." Social Science Quarterly 82(3): 536-551.

Loewen, Peter John, Carolina de Miguel and Maxime Heroux-Legault. 2015. “Nationalism and Ethnic Heterogeneity: The Importance of Local Context for Nationalist Party Vote Choice." Electoral Studies. 39:129-141.

Loewen, Peter and Daniel Rubenson (2018). “Local Parliament Project 2015 Canadian Election Survey." Harvard Dataverse: https:// doi.org/10.7910/DVN/DACHKP

Marsh, Michael. 1987. “Electoral evaluations of candidates in Irish general elections 1948-82." Irish Political Studies 2(1): 65-76.

Marsh, Michael. 2004. “None of that Post-modern stuff around here: Grassroots campaigning in the 2002 Irish General Election." British Elections \& Parties Review 14(1): 245-267.

Mendelsohn, Matthew. 1993. “Television's Frames in the 1988 Canadian Election.” Canadian Journal of Communication 18(2): 149-171.

Mendelsohn, Matthew. 1996. “The Media and Interpersonal Communications: The Priming of Issues, Leaders, and Party Identification." The Journal of Politics 58(1): 112-125.

Ohr, Dieter. 2015. “Changing Patterns of Political Communication." In Political Leaders and Democratic Elections, eds. Kees Aarts, André Blais, and Hermann Schmitt. Oxford: Oxford University Press. 
Pattie, Charles J. and Ronald J. Johnston. 2003. “Hanging on the Telephone? Doorstep and Telephone Canvassing at the British General Election of 1997." British Journal of Political Science 33(2): 303-322.

Pattie, Charles J., Ronald J. Johnston and Edward A. Fieldhouse. 1995. “Winning the Local Vote: The Effectiveness of Constituency Campaign Spending in Great Britain, 19831992." American Political Science Review 89(4): 969-983.

Roy, Jason and Christopher Alcantara. 2015. “The Candidate Effect: Does the Local Candidate Matter?" Journal of Elections, Public Opinion and Parties 25(2): 195-214.

Schoen, Harald and Siegfried Schumann. 2007. "Personality Traits, Partisan Attitudes, and Voting Behavior. Evidence from Germany." Political Psychology 28(4): 471-498.

Shugart, Matthew Søberg, Melody Ellis Valdini and Kati Suominen. 2005. “Looking for Locals: Voter Information Demands and Personal Vote-Earning Attributes of Legislators under Proportional Representation." American Journal of Political Science 49(2): 437-449.

Simpson, Jeffrey. 2002. “This Turncoat MP Should Be Recalled.” The Globe and Mail: January 29, 2002, A17.

Tavits, Margit. 2010. “Effect of Local Ties On Electoral Success and Parliamentary Behaviour: The Case of Estonia." Party Politics 16(2): 215-235.

Trimble, Linda and Shannon Sampert. 2004. “Who's in the Game? The Framing of Election 2000 by The Globe and Mail and The National Post." Canadian Journal of Political Science 37(1): 51-71.

Whiteley, Paul F. and Patrick Seyd. 2003. "How to win a landslide by really trying: the effects of local campaigning on voting in the 1997 British general election." Electoral Studies 22(2): 301-324.

Wielhouwer, Peter W. and Brad Lockerbie. 1994. "Party Contacting and Political Participation, 
1952-90." American Journal of Political Science 38(1): 211-229. 